\title{
Health economic evaluation of Human Papillomavirus vaccines in women from Venezuela by a lifetime Markov cohort model
}

Ariel Esteban Bardach ${ }^{1 *}$ D, Osvaldo Ulises Garay ${ }^{1}$, María Calderón ${ }^{1}$, Andrés Pichón-Riviére ${ }^{1}$, Federico Augustovski ${ }^{1}$, Sebastián García Martí ${ }^{1}$, Paula Cortiñas ${ }^{2}$, Marino Gonzalez ${ }^{3}$, Laura T. Naranjo ${ }^{4}$, Jorge Alberto Gomez ${ }^{5}$

and Joaquín Enzo Caporale ${ }^{1}$

\begin{abstract}
Background: Cervical cancer (CC) and genital warts (GW) are a significant public health issue in Venezuela. Our objective was to assess the cost-effectiveness of the two available vaccines, bivalent and quadrivalent, against Human Papillomavirus (HPV) in Venezuelan girls in order to inform decision-makers.

Methods: A previously published Markov cohort model, informed by the best available evidence, was adapted to the Venezuelan context to evaluate the effects of vaccination on health and healthcare costs from the perspective of the healthcare payer in an 11-year-old girls cohort of 264,489. Costs and quality-adjusted life years (QALYs) were discounted at $5 \%$. Eight scenarios were analyzed to depict the cost-effectiveness under alternative vaccine prices, exchange rates and dosing schemes. Deterministic and probabilistic sensitivity analyses were performed.
\end{abstract}

Results: Compared to screening only, the bivalent and quadrivalent vaccines were cost-saving in all scenarios, avoiding 2,310 and 2,143 deaths, 4,781 and 4,431 CCs up to 18,459 GW for the quadrivalent vaccine and gaining 4,486 and 4,395 discounted QALYs respectively. For both vaccines, the main determinants of variations in the incremental costs-effectiveness ratio after running deterministic and probabilistic sensitivity analyses were transition probabilities, vaccine and cancer-treatment costs and HPV 16 and 18 distribution in CC cases. When comparing vaccines, none of them was consistently more cost-effective than the other. In sensitivity analyses, for these comparisons, the main determinants were GW incidence, the level of cross-protection and, for some scenarios, vaccines costs.

Conclusions: Immunization with the bivalent or quadrivalent HPV vaccines showed to be cost-saving or costeffective in Venezuela, falling below the threshold of one Gross Domestic Product (GDP) per capita (104,404 VEF) per QALY gained. Deterministic and probabilistic sensitivity analyses confirmed the robustness of these results.

Keywords: HPV vaccines, Cervical cancer, Genital warts, Health economic evaluation, Markov cohort model, Venezuela

\footnotetext{
* Correspondence: abardach@iecs.org.ar

${ }^{1}$ IECS Instituto de Efectividad Clínica y Sanitaria, Dr. Emilio Ravignani 2024

(C1014CPV), 1014 Buenos Aires, Argentina

Full list of author information is available at the end of the article
}

(c) The Author(s). 2017 Open Access This article is distributed under the terms of the Creative Commons Attribution 4.0 International License (http://creativecommons.org/licenses/by/4.0/), which permits unrestricted use, distribution, and reproduction in any medium, provided you give appropriate credit to the original author(s) and the source, provide a link to the Creative Commons license, and indicate if changes were made. The Creative Commons Public Domain Dedication waiver (http://creativecommons.org/publicdomain/zero/1.0/) applies to the data made available in this article, unless otherwise stated. 


\section{Background}

Cervical cancer (CC) is the fourth most common cancer in women worldwide with an estimated toll of 528,000 new cases and 266,000 deaths in 2012 [1]. In Latin America and the Caribbean region (LAC) the agestandardized incidence rates ranged from 14.6 to 44.0 per 100,000 women per year, values probably underestimated due to insufficient coverage and frequency of screening, inadequate collection and analysis of cytological samplings as well as incomplete follow-up of cases [2, 3]. The Bolivarian Republic of Venezuela is a South-American country with a population of 27.2 million people where 1 in 3 women is aged 15 years and older and are at risk of developing CC [4]. In this country, $\mathrm{CC}$ is the first most common female cancer in women aged 15 to 44 years, accounting for 1,973 new cases diagnosed in 2011 and 1,789 new CC-related deaths annually for all ages $[5,6]$.

The Human Papillomavirus (HPV) infection occurs commonly in sexually active women; it has been identified as the necessary cause of $\mathrm{CC}$ and has been associated with other types of cancer [7-9]. High-risk types of HPV (HPV 16, 18, 45, 31, 33, 39, 52, 58 and 35) have been recognized as a necessary etiological agent for the development of $\mathrm{CC}$ and premalignant cervical lesions, being detected in up to $99.7 \%$ of such cases [10-13]. Low-risk HPV types (6, 11, 34, 40, 42, 43 and 44) have been associated with genital warts (GW) and low-grade cervical lesions. Among Venezuelan women, HPV types 16 and 18 were identified as the most common high-risk HPV types with an overall prevalence of $80 \%$ in patients with $C C[14,15]$. It is established that CC comprehensive prevention approaches, including well-organized cervical screening programs using Papanicolaou smear tests (Pap), can reduce CC incidence and mortality [16]. Additionally, the introduction of HPV vaccination is expected to also reduce the burden of CC [17]. Currently, there are two available vaccines: a bivalent vaccine targeting high-risk HPV 16 and 18 (Cervarix ${ }^{\text {тм }}$, GSK) and quadrivalent vaccine targeting, in addition to the above, also low-risk HPV 6 and 11 types (Gardasil, Merck) [18]. Both vaccines have proven efficacy in the prevention of lesions associated with the HPV types they target $[19,20]$.. Currently in Venezuela, there is a nationwide CC screening program including Paps for women of 25 to 65 years old. However, the HPV vaccine has not yet been incorporated into the national vaccination program and consequently, there is no vaccination coverage $[5,21]$.

Cost-effectiveness analysis is a useful tool to assist decision makers in assessing the value of specific interventions and inform resource-allocation decisions. Several models based on economic evaluations have been conducted to assess the cost-effectiveness of interventions that reduce $\mathrm{HPV}$-associated premalignant and malignant lesions in Latin America, including vaccination [22, 23]. The results of the analyses vary widely from country to country due to differences in epidemiological factors such as the incidence of certain HPV-related diseases, local treatment patterns and related costs [22]. Therefore, a country-specific assessment needs to be conducted in order to suitably inform local decision-makers.

The aim of the present study was to perform an economic evaluation based on a cohort model adapted to estimate the lifetime cost and clinical outcomes of vaccination with the bivalent and quadrivalent vaccination schemes, comparing them with the current policy in Venezuela of no vaccination.

\section{Methods}

\section{Model structure}

A previously published lifetime Markov cohort model with a 1-year cycle was adapted to reflect the Venezuelan setting. The model simulated the natural history of oncogenic HPV in CC, the effect of screening and the impact of vaccination over the lifetime of the cohort. [24-26] The current model has been extended to include infection with low-risk HPV types (HPV 6 and HPV 11) that might progress to cervical intraepithelial neoplasia grade 1 (CIN1) and/or to GW (Fig. 1) [18, 27]. The perspective was stated as of the healthcare payer including direct medical costs only. The analysis allowed the estimation of costs and effects of each of the three intervention strategies: current screening program, current screening program in addition to vaccination with the bivalent vaccine, and current screening program in addition to vaccination with the quadrivalent vaccine. For this analysis, a lifetime horizon was adopted. In order to reflect the range of possible results taking into account different vaccine costs, alternative exchange rates for Venezuela, and 2-dose schedule vs. 3-dose schedule, eight scenarios were considered for the base-case analyses, as detailed in the following sections.

\section{Input parameters}

An extensive review of the literature was done in MEDLINE and LILACS. Local information related to epidemiology, use of resources and costs associated to HPV-lesions treatment was collected. Priority to local sources of information was given. Selected parameters were used to populate the model and were reviewed and validated by experts. Input parameters included are summarized in Table 1.

\section{Vaccinated population and coverage}

Based on demographic data from the National Institute of Statistics of Venezuela, the model included a cohort of girls aged 11 years $(n=264,489)$ [4]. Vaccination coverage was assumed to reach $95 \%$ for a 3 dose scheme 


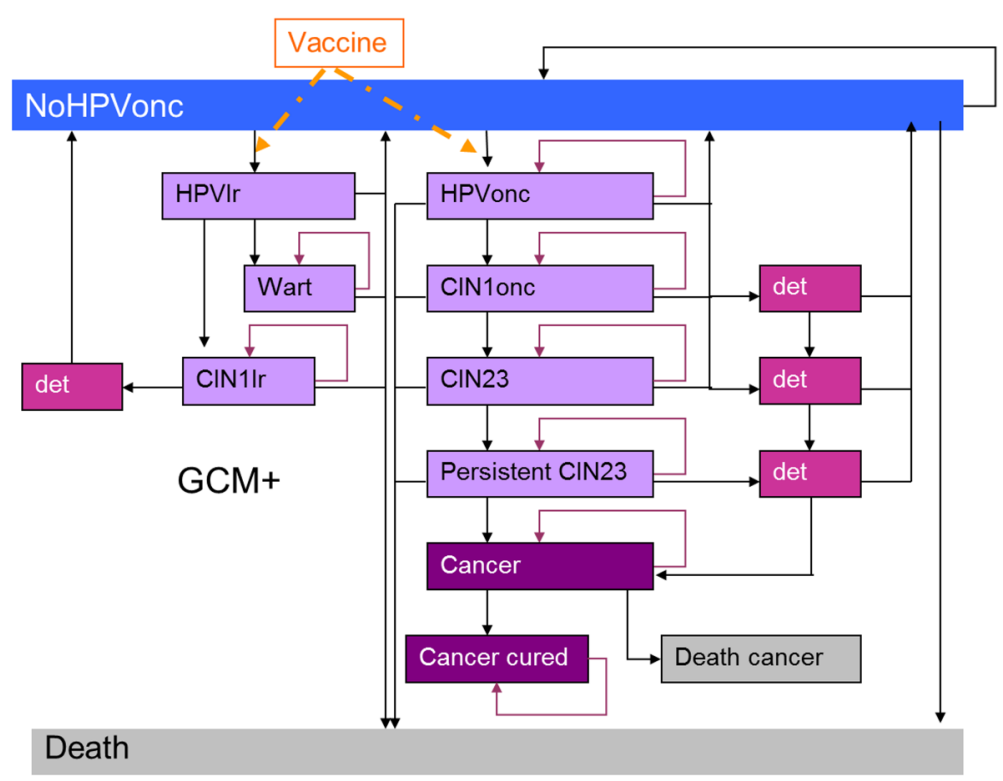

Fig. 1 Model structure. Abbreviations: GCM+: Gardasil-Cervarix Model; CIN1onc, cervical intraepithelial neoplasia 1 oncogenic; CIN1Ir, low-risk cervical intraepithelial neoplasia 1; det, CIN health state detected through screening: same pathways as CIN nondetected CIN health state but with different probabilities; HPV, human papillomavirus; HPVIr, low-risk HPV infection; HPVonc, oncogenic HPV infection; NoHPVonc, no oncogenic HPV infection, CIN2/3, cervical intraepithelial neoplasia 2 or 3

$[5,21]$, similar to what was previously assumed for an economic evaluation using the same model in Chile and the coverage observed for other vaccines in the country [28].

\section{Epidemiological data}

The general mortality rate by age in Venezuelan women was calculated from overall deaths and distribution of female population in 2011 [4, 6]. Number of deaths, overall mortality rate and mortality rate stratified by age were obtained from the National Mortality Yearbook of the Ministry of Health of Venezuela [6]. The age-specific incidence of high- and low-risk HPV was calculated based on data from a Venezuelan study [29] and adjusted to an age-specific tendency shown in a Chilean population-based study [30]. Data for GW incidence were scarce in the region; thus, the age-specific incidence of GW was matched to data reported in a large German population-based cohort study [31], in which the incidence is in average what is reported for many countries [32]. Data on type-specific distribution of HPV in CIN1, CIN2/3 and CC were obtained from Correnti et al. [14] and Sanchez-Lander et al. [15] Distribution of HPV 6 and 11 in GW was obtained from Avila et al. [33] Data on CIN1 and CIN2/3 natural history were obtained from Petry [34]. Information on treatment outcomes was provided by Melnikow et al. [35] and by local experts. Five-year CC cure rate for Venezuela was set on $41.5 \%$, according to Rodriguez et al. [36] The coverage of regular screening of Pap was reported to be 35\% every 3 years from age 25 to 64 years old [21,37] and the percentage of positive Pap per screening campaign was $5 \%$ based on local experts opinion. Pap-smear-testoperative characteristics for CIN1 and CIN2/3 were obtained from Colantonio et al. [22]

\section{Treatment costs}

The model requires cost data for five health events' treatments: screening, CIN1, CIN2/3, genital warts and cancer. In all cases we estimated expected costs using a micro-costing approach, which required to identify the resources used, the intensity of use and their unit costs. The list of resources were obtained from local literature [38] and their expected use was estimated using annual utilization rates obtained from administrative databases of Dr. Luis Razetti Oncologic Institute from Caracas, Venezuela, and validated through an expert opinion. All unit costs are of 2015 and were obtained from five local private health facilities, two of them of primary health care where $85 \%$ of the population with private coverage usually attend, while three with a high complexity level. Public tariffs were approximated from the last available Gaceta Oficial [39] and a private ambulatory health facility similar in costs. Finally, tariffs were weighted according to the distribution of utilization of public (74\%) and private (26\%) institutions [40]. When necessary costs were adjusted using the national Consumer Price Index [41] Details about unit costs, expected quantities and expected costs, treatment costs, vaccination costs per scenario and total costs (micro-costing) can be found in the Additional file 1. 
Table 1 Input data values: base-case values, associated ranges, probabilities distributions assumed and sources

\begin{tabular}{|c|c|c|c|}
\hline \multirow{2}{*}{$\frac{\text { Inputs }}{\text { Population data }}$} & \multicolumn{2}{|l|}{ Value (range) } & \multirow[t]{2}{*}{ Source } \\
\hline & & & \\
\hline 11-years old women cohort & 264,489 & - & [4] \\
\hline \multicolumn{4}{|l|}{ Transition probabilities } \\
\hline HPV onc regression & $0.50(0.23 ; 0.77)$ & Uniform $(0.23 ; 0.77)$ & {$[18,64]$} \\
\hline HPV onc to CIN1 progression & $0.05(0.03 ; 0.07)$ & Normal $(0.03 ; 0.07)$ & {$[18,64]$} \\
\hline CIN1 onc regression & $0.36(0.22 ; 0.78)$ & Normal $(0.22 ; 0.78)$ & {$[18,64]$} \\
\hline CIN1 onc to CIN2/3 progression & $0.14(0.08 ; 0.16)$ & Normal $(0.08 ; 0.16)$ & {$[18,64]$} \\
\hline $\mathrm{CIN} 2 / 3$ regression to no HPV & $0.25(0.23 ; 0.32)$ & Normal $(0.23 ; 0.32)$ & {$[18,64]$} \\
\hline CIN2/3 progression to cancer & $0.14(0.10 ; 0.15)$ & Normal $(0.10 ; 0.15)$ & {$[18,64]$} \\
\hline HPV low-risk CIN1 & $0.04(0.03 ; 0.05)$ & Normal $(0.03 ; 0.05)$ & {$[18,64]$} \\
\hline Genital wart resistance & $0.35(0.28 ; 0.42)$ & Uniform $(0.28 ; 0.42)$ & [65] \\
\hline Proportion CIN1 onc detected and treated & $0.30(0.24 ; 0.36)$ & Uniform $(0.24 ; 0.36)$ & Exp. Op \\
\hline CIN1 treatment success & $0.94(0.75 ; 1.00)$ & Uniform $(0.75 ; 1.00)$ & [35] \\
\hline Proportion CIN2/3 detected and treated & $0.90(0.72 ; 1.00)$ & Uniform $(0.72 ; 1.00)$ & Exp. Op \\
\hline CIN2/3 treatment success & $0.88(0.70 ; 1.00)$ & Uniform (0.70; 1.00) & [35] \\
\hline \multicolumn{4}{|l|}{ Utility weights } \\
\hline No HPV & 1.000 & - & [18] \\
\hline HPV & 1.000 & - & [18] \\
\hline Genital Wart & $0.02(0.02 ; 0.02)$ & Uniform $(0.02 ; 0.02)$ & [18] \\
\hline CIN1 & 1.000 & - & [18] \\
\hline CIN1 detected & $0.01(0.01 ; 0.02)$ & Uniform $(0.01 ; 0.02)$ & [18] \\
\hline $\mathrm{CIN} 2 / 3$ & 1.000 & - & [18] \\
\hline $\mathrm{CIN} 2 / 3$ detected & $0.01(0.01 ; 0.01)$ & Uniform $(0.01 ; 0.01)$ & [18] \\
\hline Cancer & $0.27(0.22 ; 0.33)$ & Uniform $(0.22 ; 0.33)$ & [18] \\
\hline Cancer cured & $0.06(0.05 ; 0.07)$ & Uniform $(0.05 ; 0.07)$ & [18] \\
\hline Death & 0.000 & - & [18] \\
\hline \multicolumn{4}{|l|}{ Screening Characteristics } \\
\hline Regular screening coverage & $35 \%$ & - & [21] \\
\hline Interval between regular screening & 3 years ( $\&$ scenario of $5 y$ ) & - & [37] \\
\hline Irregular screening coverage & $25 \%$ & - & Exp. Op \\
\hline Population without screening & $40 \%$ & - & Exp. Op \\
\hline Age of initiation of screening & 25 years & - & [21] \\
\hline Sensitivity to detect CIN1 & $0.58(0.38 ; 0.56)$ & Normal $(0.38 ; 0.56)$ & [22] \\
\hline Sensitivity to detect CIN2 and CIN3 & $0.61(0.69 ; 0.87)$ & Normal $(0.69 ; 0.87)$ & [22] \\
\hline Estimated positive Pap smear & $0.05(0.05 ; 0.06)$ & Uniform $(0.04 ; 0.06)$ & Exp. Op \\
\hline \multicolumn{4}{|l|}{ Parameters to estimate vaccine effectiveness } \\
\hline Prevalence of HPV types 16 and 18 in cervical cancer & $0.80(0.64 ; 0.96)$ & Uniform $(0.64 ; 0.96)$ & [15] \\
\hline Prevalence of other oncogenic HPV in cervical cancer & $0.16(0.13 ; 0.19)$ & Uniform $(0.13 ; 0.19)$ & [15] \\
\hline Prevalence of HPV types 16 and 18 in CIN2/3 & $0.55(0.44 ; 0.66)$ & Uniform $(0.44 ; 0.66)$ & [14] \\
\hline Prevalence of other oncogenic HPV in CIN2/3 & $0.34(0.27 ; 0.41)$ & Uniform $(0.27 ; 0.41)$ & [14] \\
\hline Prevalence of HPV types 16 and 18 in CIN1 & $0.27(0.21 ; 0.32)$ & Uniform $(0.21 ; 0.32)$ & [14] \\
\hline Prevalence of other oncogenic HPV in CIN1 & $0.28(0.22 ; 0.33)$ & Uniform $(0.22 ; 0.33)$ & [14] \\
\hline Prevalence of HPV types 6 and 11 in CIN1 & $0.14(0.11 ; 0.17)$ & Uniform $(0.11 ; 0.17)$ & [14] \\
\hline Prevalence of HPV types 6 and 11 in GW & $0.95(0.76 ; 1.00)$ & Uniform $(0.76 ; 1.00)$ & [33] \\
\hline
\end{tabular}


Table 1 Input data values: base-case values, associated ranges, probabilities distributions assumed and sources (Continued)

\begin{tabular}{|c|c|c|c|}
\hline Vaccine efficacy to HPV types 16 and 18 CC (Bivalent) & $0.98(0.94 ; 1.00)$ & Normal $(0.94 ; 1.00)$ & {$[43,44]$} \\
\hline Vaccine efficacy to HPV types 16 and 18 CC (Quadrivalent) & $0.98(0.94 ; 1.00)$ & Normal $(0.94 ; 1.00)$ & [45] \\
\hline Vaccine efficacy to HPV types 16 and 18 CIN2/3 (Bivalent) & $0.98(0.97 ; 0.99)$ & Normal $(0.97 ; 0.99)$ & {$[43,44]$} \\
\hline Vaccine efficacy to HPV types 16 and 18 CIN2/3 (Quadrivalent) & $0.98(0.97 ; 0.99)$ & Normal $(0.97 ; 0.99)$ & [45] \\
\hline Vaccine efficacy to HPV types 16 and 18 CIN1 (Bivalent) & $0.98(0.97 ; 0.99)$ & Normal $(0.97 ; 0.99)$ & {$[43,44]$} \\
\hline Vaccine efficacy to HPV types 16 and 18 CIN1 (Quadrivalent) & $0.98(0.97 ; 0.99)$ & Normal $(0.97 ; 0.99)$ & [45] \\
\hline Vaccine efficacy to other oncogenic HPV CC (Bivalent) & $0.68(0.68 ; 0.68)$ & Normal $(0.68 ; 0.68)$ & {$[47-50]$} \\
\hline Vaccine efficacy to other oncogenic HPV CC (Quadrivalent) & $0.33(0.33 ; 0.33)$ & Normal $(0.33 ; 0.33)$ & [46] \\
\hline Vaccine efficacy to other oncogenic HPV CIN2/3 (Bivalent) & $0.68(0.68 ; 0.68)$ & Normal $(0.68 ; 0.68)$ & {$[47-50]$} \\
\hline Vaccine efficacy to other oncogenic HPV CIN2/3 (Quadrivalent) & $0.33(0.33 ; 0.33)$ & Normal $(0.33 ; 0.33)$ & [46] \\
\hline Vaccine efficacy to other oncogenic HPV CIN1 (Bivalent) & $0.48(0.48 ; 0.48)$ & Normal $(0.48 ; 0.48)$ & {$[47-50]$} \\
\hline Vaccine efficacy to other oncogenic HPV CIN1 (Quadrivalent) & $0.23(0.23 ; 0.23)$ & Normal $(0.23 ; 0.23)$ & [46] \\
\hline Vaccine efficacy to HPV types 6 and 11 (Quadrivalent) & $0.98(0.94 ; 1.00)$ & Normal $(0.94 ; 1.00)$ & {$[66,67]$} \\
\hline GW incidence (10-79 years) & $0.17 \%(0.089 ; 0.245)$ & Truncated Normal (Mean; range) & [31] \\
\hline \multicolumn{4}{|l|}{ Costs } \\
\hline Regular screening (Bs.F) & $\$ 2,943(2,207 ; 3,678)$ & Uniform $(2,207 ; 3,678)$ & \multirow[t]{10}{*}{ see costs section } \\
\hline CIN1Onc newly detected (Bs.F) & $\$ 20,749(15,562 ; 25,936)$ & Uniform $(15,562 ; 25,936)$ & \\
\hline CIN2/3 newly detected (Bs.F) & $\$ 22,230(16,672 ; 27,787)$ & Uniform $(16,672 ; 27,787)$ & \\
\hline CIN1Onc det (Bs.F) & $\$ 15,284(11,463 ; 19,105)$ & Uniform $(11,463 ; 19,105)$ & \\
\hline CIN2/3 det (Bs.F) & $\$ 28,355(21,266 ; 35,444)$ & Uniform $(21,266 ; 35,444)$ & \\
\hline Cancer (Bs.F) & $\$ 273,788(205,341 ; 342,234)$ & Uniform $(205,341 ; 342,234)$ & \\
\hline Genital Wart (Bs.F) & $\$ 9,568(7,176 ; 11,960)$ & Uniform $(7,176 ; 11,960)$ & \\
\hline Vaccine bivalent (per dose) (USD) & $\$ 8.5$ & - & \\
\hline Vaccine quadrivalent (per dose) USD; Scenarios 1-4 & $\$ 8.5$ & - & \\
\hline Vaccine quadrivalent (per dose) USD; Scenerios 5-8 & $\$ 13.8$ & - & \\
\hline
\end{tabular}

Abbreviations: NIS National Institute of Statistics, MoH Ministry of Health, VEF Venezuelan bolivar fuerte, US\$ United States dollar, Exp. Op expert opinion, BV bivalent, QV quadrivalent, CIN cervical intraepithelial neoplasia, CC cervical cancer, HPV human papillomavirus, VE vaccine efficacy, GW genital wart, y year

\section{Vaccine costs}

Vaccine prices per person were calculated as the unit price of vaccines multiplied by the number of doses. Delivery costs were assumed to be equal for both vaccines and therefore were not considered in the analysis. Because there was uncertainty at the time the study was done about the price that Venezuela would pay once the vaccines were incorporated into the national program, two of the scenarios were projected considering equal price per dose at US\$ 8.5 for each vaccine. The other scenario considered differential prices: US\$ 8.5 per dose of the bivalent vaccine and US\$ 13.79 per dose of the quadrivalent vaccine. These prices are based on last available Pan American Health Organization (PAHO) price agreements and projections for both vaccines, that is for 2013 [42].

\section{Exchange rates}

A key issue in the analysis is the election of the exchange rate. While expressing all values in USD or in VEF does not change results, the election of the rate does it because vaccines prices comes in USD and all the other costs are local estimations expressed in VEF. At the moment the analysis was done, there were in Venezuela several prevailing exchange rates and considering that it is not clear which one truly represents the opportunitiy costs of trading currencies, we decided to represent this uncertainty creating two scenarios for the most relevant rates: the exchange rate of 6.3 VEF per US\$ (agreement No. 14, Ministry of Health of Venezuela vaccines purchase exchange rate) and the exchange rate of $170 \mathrm{VEF}$ per US\$ (agreement No. 33, regular citizens purchase exchange rate). Hence, choosing one rate over the other makes costs vary 27 times. Vaccine prices obtained from the PAHO Revolving Fund in US\$.

\section{Vaccine efficacy and cross-protection}

For the estimation of vaccine effectiveness, HPV typespecific vaccine efficacy for both vaccines was considered as 98\% against CC, CIN1 and CIN2/3 associated with HPV 16 and 18 with a lifelong duration [43-45]. The combined efficacy of the ten most frequent oncogenic HPV non-vaccine types $(31,33,35,39,45,51,52,56,58$ and 59$)$ was 
considered jointly. Vaccine efficacy for these types, for the quadrivalent vaccine was $23.4 \%$ (95\% Confident Interval CI : 7.8-36.4) and 32.5\% (95\% CI: 6.0-51.9) for CIN1 and CIN2+, respectively [46]. Vaccine efficacy for the bivalent vaccine for these ten non-vaccine oncogenic types was 47.7\% (95\% CI 28.9 to 61.9) and 68.4 (95\% CI: 45.7 to 82.4) for CIN1 and CIN2+, respectively [47-50]. Considering the latest evidence regarding the efficacy of the 2-dose scheme, case scenarios comparing the 2-dose schedule vs. the currently approved 3-dose schedule were developed; the same level and duration of efficacy and crossprotection were considered for both regimes [51-58]. In all scenarios, the duration of cross-protection for the base-case was set at 10 years, with a 5 -year waning period.

\section{Scenarios considered}

For Venezuela, we needed to consider eight different plausible base-case scenarios, defined by the combination of a) two different official exchange rates, b) two number of doses per scheme, and c) two differential prices of vaccines (Table 2).

\section{Outcomes}

The present exercise explored health outcomes and disease-related costs for the different scenarios considered; we considered life years (LYs), QALYs, number of cervical cancer cases and deaths, number of new and recurrent genital warts, and total costs other than vaccination, including costs of screening, of CIN cases, warts and cancer cases. Another set of outcomes explored was the vaccine costs per scenario.

\section{Discounting}

The health benefits and costs were discounted at an annual rate of $5.0 \%$ based on guidelines recommendations for economic evaluations in LAC [59]. The effect of this discount rate on the outcomes was assessed in the different scenarios.

Table 2 Summary of base-case scenarios

\begin{tabular}{llll}
\hline Scenario & $\begin{array}{l}\text { Vaccine } \\
\text { Price in USD }\end{array}$ & Exchange rate & Dose scheme \\
\hline 1 & BV: $8.5-$ QV: 8.5 & 6.3 & 3 doses \\
2 & BV: $8.5-$ QV: 8.5 & 6.3 & 2 doses \\
3 & BV: $8.5-$ QV: 8.5 & 170 & 3 doses \\
4 & BV: $8.5-$ QV: 8.5 & 170 & 2 doses \\
5 & BV: $8.5-$ QV: 13.79 & 6.3 & 3 doses \\
6 & BV: $8.5-$ QV: 13.79 & 6.3 & 2 doses \\
7 & BV: $8.5-$ QV: 13.79 & 170 & 3 doses \\
8 & BV: $8.5-$ QV: 13.79 & 170 & 2 doses
\end{tabular}

For all these scenarios, the same cross protection and screening interval was assumed

Abbreviations: $B V$ bivalent, $Q V$ quadrivalent, VEF Venezuelan bolívar fuerte, US\$ United States dollar

\section{Calibration}

The model was calibrated by modifying input parameters to match the model output to the data from vital statistics of Venezuela, keeping transition probabilities within predetermined ranges of plausibility (Fig. 2). Age-specific CC incidence and mortality rates, as well as the overall number of cases and deaths estimated by the model were matched to observed vital statistics'data. On average, modeled event rates were within $+/-10 \%$ of the observed event rates. Age-specific CC incidence and mortality were graphed and the resulting estimated and observed curves were visually explored to confirm a good fit. Since up-todate cancer incidence data are likely to reflect a worse screening coverage prevailing in the past, the model was also calibrated using coverage rates representative of the Venezuelan situation 15 years ago, according to the consensus opinion of the group of authors.

\section{Deterministic and probabilistic sensitivity analysis}

Parameter uncertainty was represented with one-way and multi-way sensitivity analyses. The objective in the first case was to identify the main drivers of results. Each parameter was varied separately from its base-case value according to a specific range (Table 1) which for all parameters were defined following three strategies according to the availability of information: i) using the reported confidence intervals when possible ii) approximating them using the percentage of variations reported in other studies $[22,60]$ iii) approximating them based on expert opinions.. The analysis was performed for the eight scenarios and summarized in tornado diagrams for costs and QALYs separately. Since the construction of the eight scenarios affects only costs, we included one tornado diagram for QALYs. (see Appendix) The probabilistic exercise was performed for each scenario to quantify the effect of uncertainty surrounding the model input parameters and to calculate probabilities of being cost-effective. In every case 1,000 simulations were generated to produce a distribution of the model results (Table 1) and was performed comparing both bivalent and quadrivalent vaccines vs. screening alone and bivalent vs. quadrivalent vaccines schemes. Simulations were plotted on the cost-effectiveness plane and used to construct cost-effectiveness acceptability curves (CEAC). These curves depict the probability of being the costeffective option of the three (to have a higher monetary benefit) [61] for each intervention according to different units of GDP per capita as threshold values. The values the curves show can be interpreted as the probabilities of being the preferred option at different costeffectiveness thresholds [62]. Only scenarios 2 and 4 (same vaccine price with 2-dose schemes) were presented for sensitivity analyses, and the rest can be found in the additional online material. 

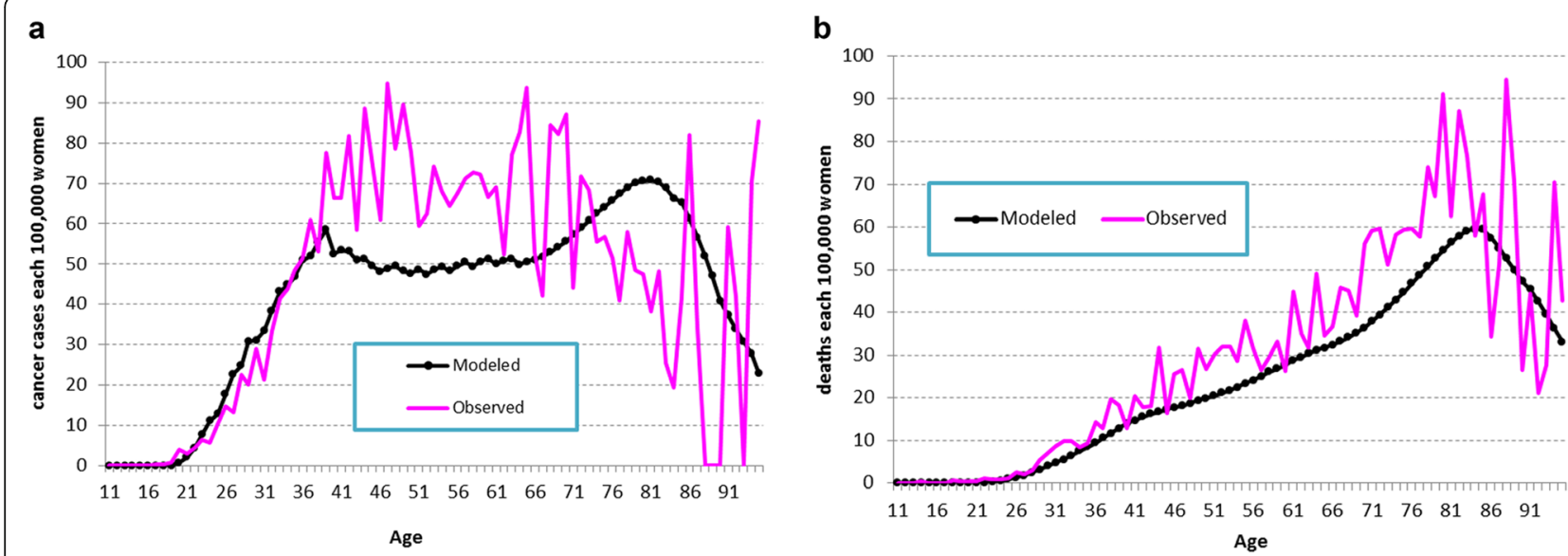

Fig. 2 Model calibration. Observed vs. model predicted values. Incidence (a) and mortality (b) of invasive cervical cancer in Venezuela predicted by the model and observed by Globocan and National Health Statistics

\section{Results}

\section{Calibration}

The model was calibrated to properly reflect the epidemiology of Venezuela. The model predicted rates of CC incidence and deaths closely matched to the incidence data for invasive CC reported by Globocan 2012 [63] and the mortality data for invasive $\mathrm{CC}$ reported by the National Mortality Yearbook of the Ministry of Health of Venezuela [6], as shown in Fig. 2. The difference between the observed and the modeled cumulative CC cases and deaths was below $10 \%$.

For the cohort of 264,489 girls, the most important health outcomes and disease-related costs, discounted and undiscounted, are depicted in Table 3-A. These results show the differential gains between bivalent vaccine vs. no vaccination, quadrivalent vaccine vs. no vaccination and both vaccines against each other. Also, these results do not differ between scenarios, as their differences are mainly due to vaccine-related costs and exchange rates used for the different scenarios. Independently of the type of vaccine considered, there are gains in QALYs, life-years (LYs), CC cases and prevented deaths as compared to no vaccination, both considering discounted and undiscounted results. When comparing both vaccines against each other, the bivalent vaccine gains 3,544 undiscounted additional QALYs vs. the quadrivalent vaccine. Also, there are fewer $\mathrm{CC}$ cases and related deaths with the bivalent vaccine than with the quadrivalent for both undiscounted and discounted results. Regarding GWs, the quadrivalent prevented 18,469 new and recurrent GW cases (not discounted). Excluding the costs of vaccination, total medical costs for bivalent vaccine are slightly higher in the discounted scenario and lower in the undiscounted, when compared to the quadrivalent vaccine. The overall cost of the different vaccination programs for each scenario are presented in Table 3-B for the 2-dose scheme scenarios $(2,4)$ and in Additional file 1: Table S2 for the 3-dose scheme scenarios (1, 3, 5 and 7) and 2-dose scheme scenario with differential pricing for vaccines.

Discounted results for incremental QALYs, costs and cost-effectiveness ratios between bivalent and quadrivalent vs. no vaccination strategies and vaccines against each other (considering different scenarios for the vaccine costs) are summarized in Table 4 and Additional file 1: Table S3. Whatever vaccine-cost scenario is considered, any vaccination strategy is cost-saving or cost-effective compared with the status quo (no vaccination) using a 1 GDP per capita threshold. When comparing the bivalent vs. the quadrivalent vaccines, ICERs showed that there were small differences between them for the first six scenarios; however, when different prices per dose are considered, under and at an exchange rate equal to 170 VEF per US\$, the bivalent strategy is dominant (Scenarios 7 and 8).

\section{Deterministic sensitivity analyses}

Tornado graphs for QALYs differences (Fig. 3) resulted in similar shapes for bivalent and quadrivalent vaccination strategies when compared to no vaccination. Discount rate was the main determinant due to differential horizon of costs and benefits, followed by transition probabilities. When comparing bivalent vs. quadrivalent strategies, the differences in QALYs ( $\mathrm{x}$-axis) were lower. Once again, the discount rate was the main determinant of variation. Cross-protection was the second parameter in importance and had a symmetrical and inverse impact over incremental QALY; that is, when no cross-protection was assumed, difference in QALY became lower and more negative, but when we considered a lifetime crossprotection, the impact was not so relevant in magnitude. These variations in assumptions do not change the conclusion that vaccines are cost-effective vs. screening alone. 
Table 3 Base-case analysis

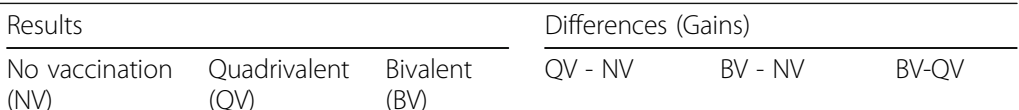

A: Health outcomes and disease-related costs Undiscounted

LYS

QALYS

Cervical cancer cases

Cervical cancer deaths

Genital Warts (new and recurrent)

Total cost other than vaccination ${ }^{\mathrm{a}}$

Costs of screening

Costs of CIN 1

Costs of CIN 2/3

Costs of warts

Costs of cancer

Discounted (5\%)

LYS

QALYS

Total cost other than vaccination ${ }^{\mathrm{a}}$

Costs of screening

Costs of CIN 1

Costs of CIN 2/3

Costs of warts

Costs of cancer

B: Vaccine costs per scenario ${ }^{a}$

2: Both vaccines $=8.5$ US\$; 2-dose scheme - FX 6.3

4: Both vaccines $=8.5$ US\$; 2-dose scheme - FX: 170

6: BV: 8.5 US\$ QV: 13.79 US\$; 2-dose scheme - FX 6.3

8: BV: 8.5 US\$ QV: 13.79 US\$; 2-dose scheme - FX: 170
$18,351,285$

$18,337,584$

7,398

3,701

21,025

$11,295.9 \mathrm{VEF}$

4,323.0 VEF

601.4 VEF

262.3 VEF

309.2 VEF

$5,800.1$ VEF

$18,395,244$

$18,390,430$

2,967

1,558

2,566

7,109.9 VEF

4,396.1 VEF

303.3 VEF

122.7 VEF

37.7 VEF

2,250.1 VEF

$5,277,952$

$5,276,066$

2,435.2 VEF

1,130.3 VEF

167.1 VEF

79.5 VEF

136.7 VEF

921.6 VEF

$5,281,034$
$5,280,461$
$1,602.7$ VEF
$1,151.9$ VEF
82.8 VEF
35.2 VEF
16.7 VEF
316.0 VEF

0 VEF

0 VEF

0 VEF

$O$ VEF

26.9 VEF

726.2 VEF

43.7 VEF

1,178.1 VEF

(BV)

\section{$18,398,735$}

$18,393,973$

2,616

1,391

21,025

7,107.3 VEF

4,383.3 VEF

344.9 VEF

102.6 VEF

309.3 VEF

$1,967.3$ VEF

$5,281,282$

$5,280,552$

3,082

4,395

1,672.5 VEF

-832.6 VEF

$1,148.5 \mathrm{VEF} \quad 21.6 \mathrm{VEF}$

91.8 VEF

28.6 VEF

136.7 VEF

-84.3 VEF

-44.3 VEF

-120.0 VEF

266.9 VEF

-605.6 VEF

26.9 VEF

26.9 VEF

726.2 VEF

726.2 VEF

26.9 VEF

43.7 VEF

726.2 VEF

$1,178.1 \mathrm{VEF}$

Abbreviations: NV no vaccination, QV quadrivalent, BV bivalent, FX foreign exchange rate (VEF per US\$), CC cervical cancer. (See scenarios 1, 3, 5, 7 in Additional file 1: Table S2), VEF Venezuelan bolívar fuerte, QALYS quality-adjusted life years, LYs life-years, CIN cervical intraepithelial neoplasia, US\$ United States dollar ${ }^{a}$ Costs are expressed in millions of VEF, 2015

Table 4 Total QALYs, total costs, and incremental cost-effectiveness ratios for scenarios 2, 4, 6 and $8^{\text {a }}$

\begin{tabular}{|c|c|c|c|c|c|c|c|c|c|}
\hline \multirow[t]{2}{*}{ Scenario } & \multicolumn{3}{|c|}{ Quadrivalent vs No vaccination } & \multicolumn{3}{|c|}{ Bivalent vs No vaccination } & \multicolumn{3}{|c|}{ Bivalent vs Quadrivalent } \\
\hline & $\triangle Q A L Y S$ & $\triangle$ COSTS & ICER & $\triangle \mathrm{QALYS}$ & $\triangle$ COSTS & ICER & $\triangle Q A L Y S$ & $\triangle$ COSTS & ICER \\
\hline \multicolumn{10}{|l|}{ Scenario } \\
\hline $\begin{array}{l}\text { 2: Both vaccines = } 8.5 \text { US\$; } \\
\text { 2-dose scheme - FX } 6.3\end{array}$ & 4,395 & -805.7 US\$ & cost-saving & 4,486 & -735.9 VEF & cost- saving & 91 & 69.8 VEF & 0.77 \\
\hline $\begin{array}{l}\text { 4: Both vaccines = } 8.5 \text { US\$; } \\
\text { 2-dose scheme - FX: } 170\end{array}$ & & -106.4 US\$ & cost- saving & & -36.6 VEF & cost- saving & & 69.8 VEF & 0.77 \\
\hline $\begin{array}{l}\text { 6: BV: } 8.5 \text { US\$ QV: } 13.79 \text { US\$; } \\
\text { 2-dose scheme - FX } 6.3\end{array}$ & & -788.9 US\$ & cost- saving & & $-735.9 \mathrm{VEF}$ & cost- saving & & 53.0 VEF & 0.58 \\
\hline $\begin{array}{l}\text { 8: BV: } 8.5 \text { US\$ QV: } 13.79 \text { US\$; } \\
\text { 2-dose scheme - FX: } 170\end{array}$ & & 345.5 US\$ & 0.08 & & -36.6 VEF & cost-saving & & $-382.1 \mathrm{VEF}$ & cost-saving \\
\hline
\end{tabular}

Notes: Results for a cohort of 264,489 women (discount $=5 \%$ )

Abbreviations: FX exchange rate (VEF per US\$), QV quadrivalent, BV bivalent. GDP per capita: 104,404 VEF. [68] (See scenarios 1, 3, 5, 7 in Additional file 1: Table S2), QALYs quality-adjusted life years, ICER incremental cost-effectiveness ratio, VEF Venezuelan bolívar fuerte, US\$ United States dollar

${ }^{a}$ Costs and ICERs are expressed in millions of VEF, 2015 


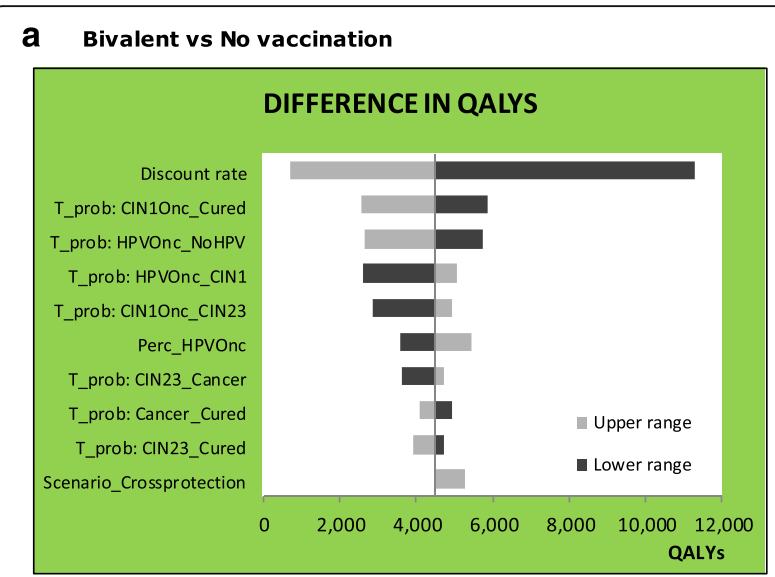

b Quadrivalent vs No vaccination

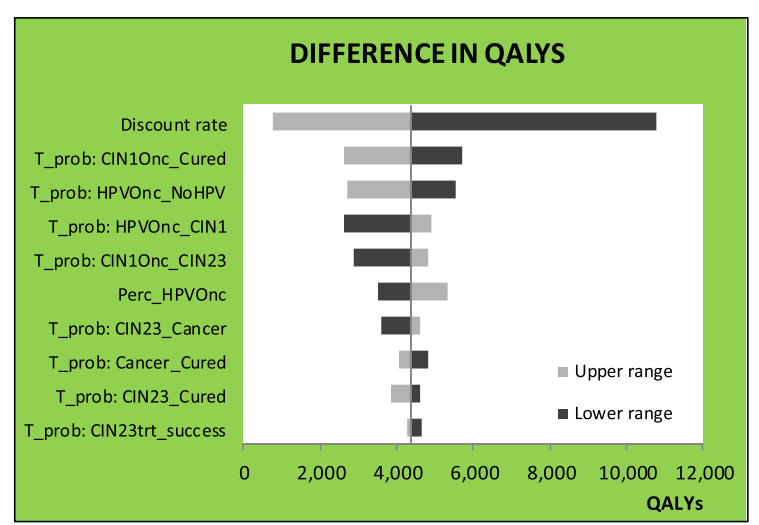

C Bivalent vs Quadrivalent

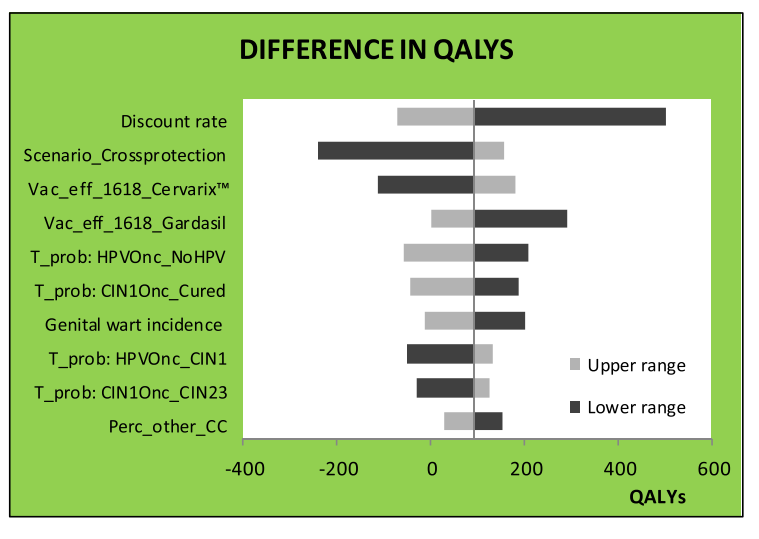

Fig. 3 Deterministic Sensitivity Analysis: Tornado graph for QALYS differences. Discount rate $=5 \%$. Abbreviations: T_pob: HPVIr_NoHPV $=$ transition probability to regress from low risk HPV to no HPV; Scenario_Crossprotection $=$ refers to the presence of lifetime crossprotection or no cross-protection at all; T_prob: HPVOnc_NoHPV = Transition probability to regress from infection with oncogenic HPV to no HPV; T_prob: HPVOnc_CIN1 = Transition probability to progress from infection with oncogenic HPV to CIN1; T_prob: CIN1Onc_CIN2/3 = Transition probability to progress from infection with oncogenic HPV and CIN1 to CIN2/3; T_prob: CIN2/3_Cancer = Transition probability to progress from CIN2/3 to cancer; $T$ _pprob: CIN1Onc_cured = Transition probability to cure from oncogenic HPV infection with CIN1; T_prob: CIN2/3_Cured = Transition probability to cure from CIN2/3; T_prob: Cancer_Cured = Transition probability to cure from cervical cancer; Vac_efficacy_1618_Cervarix = Vaccine efficacy for oncogenic types with quadrivalent vaccine; Vac_efficacy_ 1618_Gardasil = Vaccine efficacy for oncogenic types with bivalent vaccine; Vac_eff_other_Gardasil = Vaccine efficacy for non-vaccine oncogenic HPV types with bivalent vaccine; Perc_HPV_6_11 = Proportion of HPV 6 and 11 in genital warts; Perc_other_CC = Proportion of non-vaccine oncogenic HPV types among Cervical Cancer; Perc_HPVOnc = Proportion of HPV 16 and 18 among Cervical Cancer; QALYs: quality-adjusted life years; HPV: Human Papillomavirus

Tornados graphs corresponding to the 2-dose scheme analysis (scenarios 2 and 4) are presented in Fig. 4 and 3-dose scheme analysis (scenarios 1, 3, 5 and 7) and scenarios with different vaccine prices with 2-dose scheme can be found in the Additional file 1. No parameter can modify the cost-saving results when any vaccine is compared with no vaccination in scenarios 2 and 6 . There are several parameters than can modify the cost-saving result when any vaccine is compared with no vaccination in scenario 4 or when the bivalent vaccine is compared with no vaccination in scenario 8 (the most significant ones are the discount rate and the transition probabilities). Finally, only the discount rate can modify the result that the quadrivalent vaccine requires a positive investment in order to generate a cost-saving result (as shown for the bivalent vaccine) in scenario 8 . The sensitivity analysis between vaccines showed that no parameter could modify the result that the quadrivalent vaccine was more costly than the bivalent vaccine in scenarios 2 and 6 . The costs of both vaccines are the only parameters that can modify the result that the quadrivalent vaccine is more costly than the bivalent vaccine in scenario 4 . Finally, no parameter can modify the result that the bivalent vaccine is less costly than the quadrivalent vaccine in scenario 8 .

\section{Probabilistic sensitivity analyses}

Cost-effectiveness plane and CEACs for interventions are presented in Fig. 5 for the scenarios 2 and 4. The other scenarios can be found in the Additional file 1. In each scenario, a first scatter-plot graph shows the results for both vaccines vs. no vaccination, and a second one shows the comparison of the vaccines against each other, 


\section{a Scenario 2}

a) Bivalent vs No vaccination

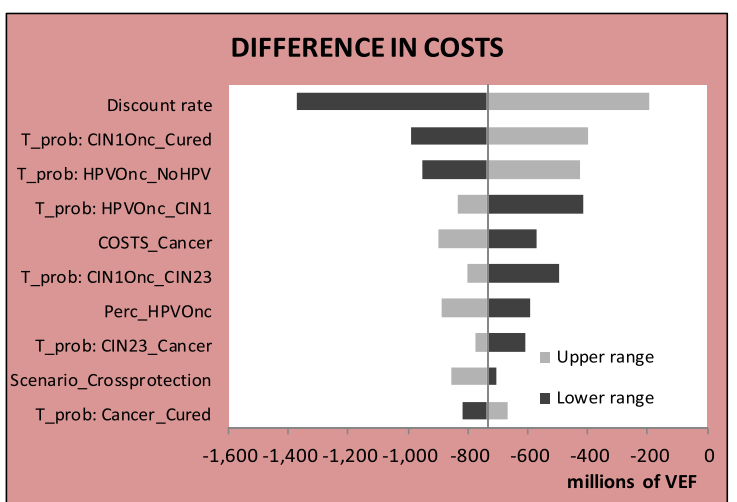

b) Quadrivalent vs No vaccination

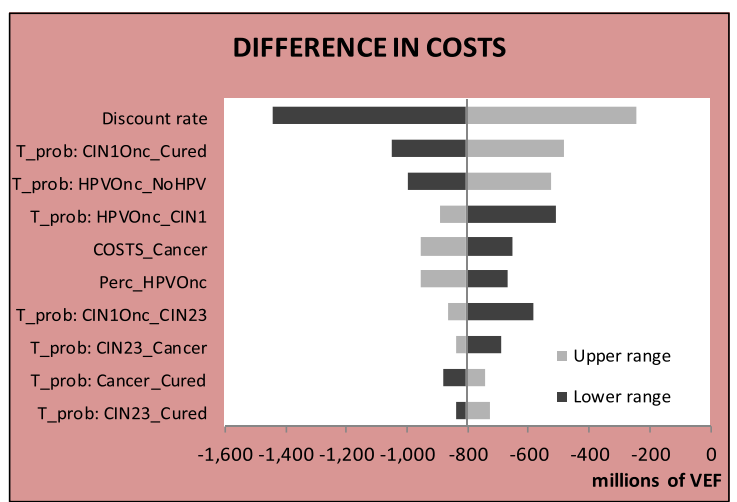

C) Bivalent vs Quadrivalent

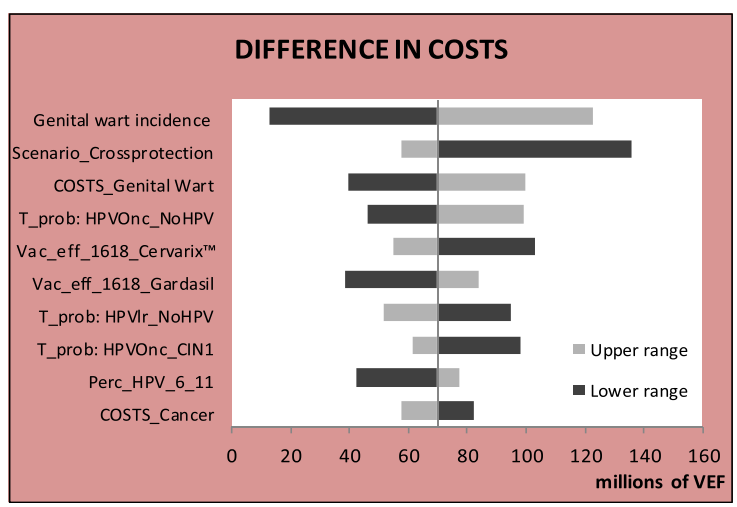

b Scenario 4

\section{a) Bivalent vs No vaccination}

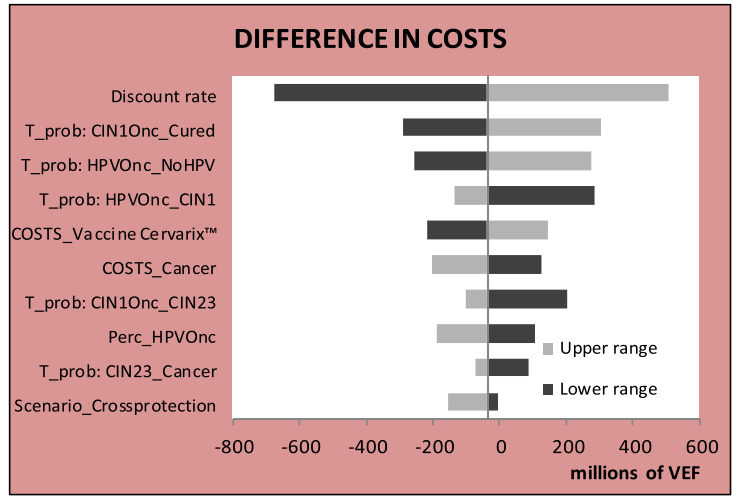

b) Quadrivalent vs No vaccination

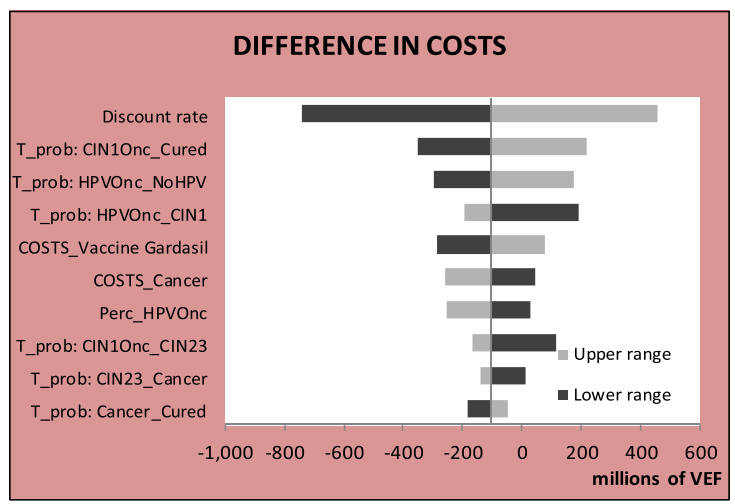

C) Bivalent vs Quadrivalent

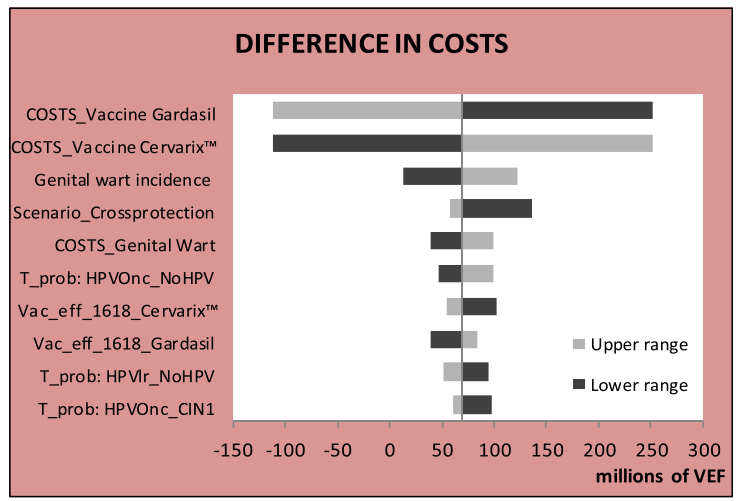

Fig. 4 (See legend on next page.) 


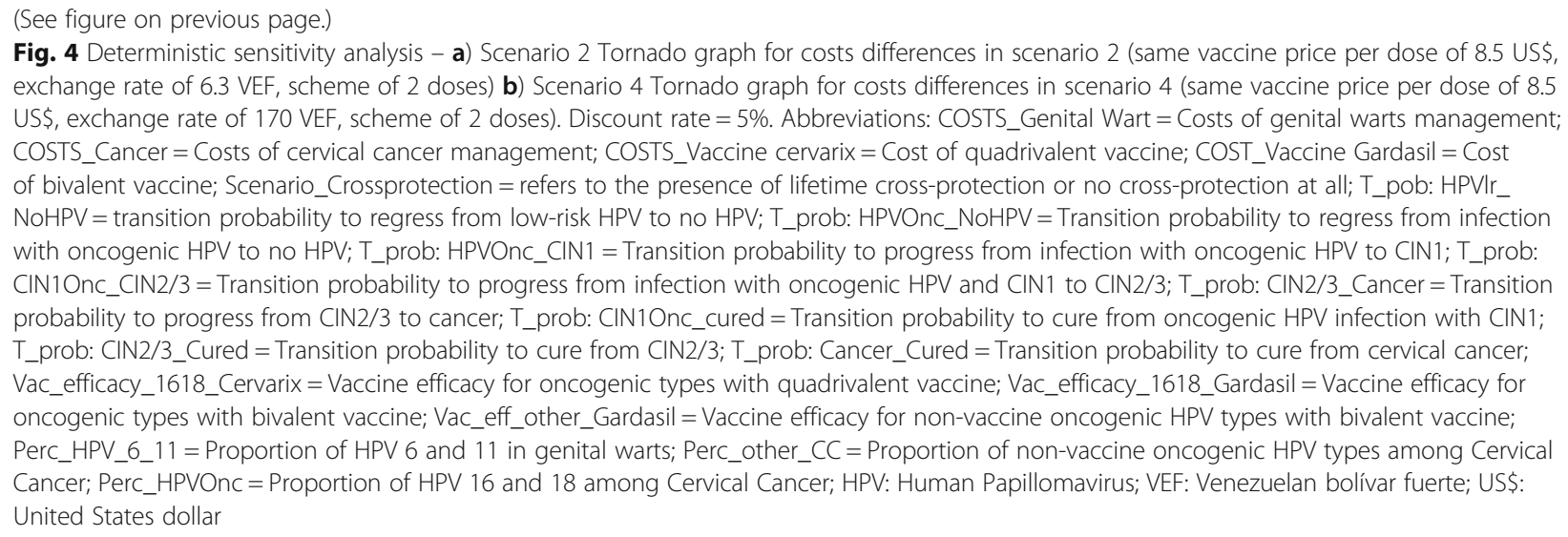

with a $5 \%$ discount rate. PSAs confirm that both vaccines are cost-saving or cost-effective vs. no vaccination considering one GDP per capita (104,404 VEF), regardless of the discount applied (data not shown). Both the scatter-plots and the acceptability curves reflect the uncertainty from the three main variables that shape the different scenarios (i.e., exchange rates, number of doses and vaccine costs) and no superiority was detected of one vaccine over the other in scenarios 2,4 and 6 . In the scenarios considering a differential vaccine cost and an exchange rate of $170 \mathrm{VEF}$ per US\$ (scenario 8), the bivalent vaccine has $64 \%$ probabilities of being dominant and $100 \%$ probabilities of being cost-saving compared to the quadrivalent vaccine. The results are very sensitive to the discount rate (data not shown).

Acceptability curves for the studied scenarios indicate the probability that the intervention is cost-effective when compared to the alternatives, according to different thresholds or monetary values of QALYs expressed as units of GDP per capita. In all cases, the curves support the results suggested by the scatter plots. When comparing both vaccination interventions to screening only, all scenarios show that vaccines options are a cost-effective choice; however, in the comparison between vaccines, the analysis becomes diffuse. In one hand, the scenarios 2, 4 and 6 show the quadrivalent vaccine as the option with the higher probabilities of being the most cost-effective choice, with a threshold of at least 1 GDP per capita. The last scenario (scenario 8) on the other hand, shows the bivalent vaccine as having the highest probability of being the most cost-effective intervention. These results suggest, therefore, that the probability of being the most costeffective intervention deeply depends on the scenario selected for analysis of exchange rate and vaccine prices.

\section{Discussion}

Our study assessed the cost-effectiveness of HPV vaccination of 11-year-old girls in Venezuela vs. status quo (current screening strategy), from the healthcare system perspective, through adapting to this country a cohort model that has been used previously in other nations $[18,28]$. Both vaccines currently available against HPV, the bivalent and the quadrivalent, were evaluated. The model was calibrated to reflect local HPV epidemiology in Venezuela.

Similarly to other studies, we faced difficulties to examine this issue in terms of the significant uncertainty of many model parameters, such as intervention, outcome costs, local epidemiological information and vaccine efficacy. Moreover, many countries are adopting a 2-dose scheme, even though the evidence is not as strong as for the 3-dose schedule.

Due to the current economic context in Venezuela, additional hurdles were to obtain adequate currency exchange rates to use (since the impact of the international price of the vaccine may vary greatly), as well as comparative vaccine prices. Though recent official prices showed that the bivalent vaccine was less costly, we considered an equal price per dose as well. So, instead of reporting a single base-case analysis, as it is usually the case in economic evaluations, and in order to incorporate these ranges of possible results, we needed to consider eight base-case scenarios including different exchange rates, different and equal vaccine prices and 2- and 3-dose schemes.

As a limitation of the model, vaccine delivery costs were not considered. However these costs do not alter results when comparing vacines, and in the scenarios versus no vaccination, the diferences observed in cost per QALY-gained are so important that the effect of including them would be within the range of what is considered cost-effective.

It is worthy to highlight that although the model was calibrated adequately with the epidemiologic value ranges reported by the Ministry of Health, the lack of accurate national information on some key parameters made us frequently use estimates from international literature and expert validation, similarly to previous 
Scenario 2

a

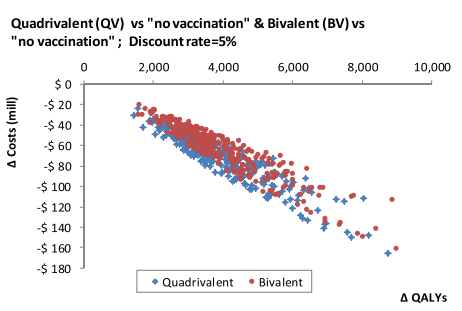

\begin{tabular}{c}
$\begin{array}{c}\text { quadrant distribution: QV } \\
0 \%: \text { :VII: } \% \%\end{array}$ \\
\hline $0 \%:$ :III II: $100 \%$
\end{tabular}$\quad \begin{gathered}\text { quadrant distribution: BV } \\
0 \%: \text { :IV|I: } 0 \%\end{gathered}$

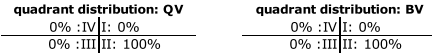

b

Bivalent vs Quadrivalent (BV-QV) Discount rate $=5 \%$

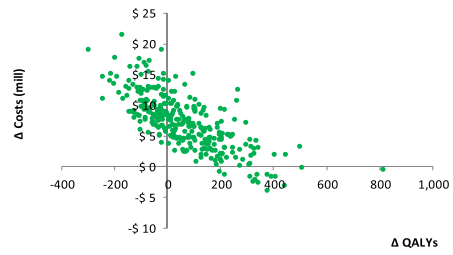

$\triangle$ QALYs

quadrant distribution

$39 \%:$ :IV|I: $56 \%$

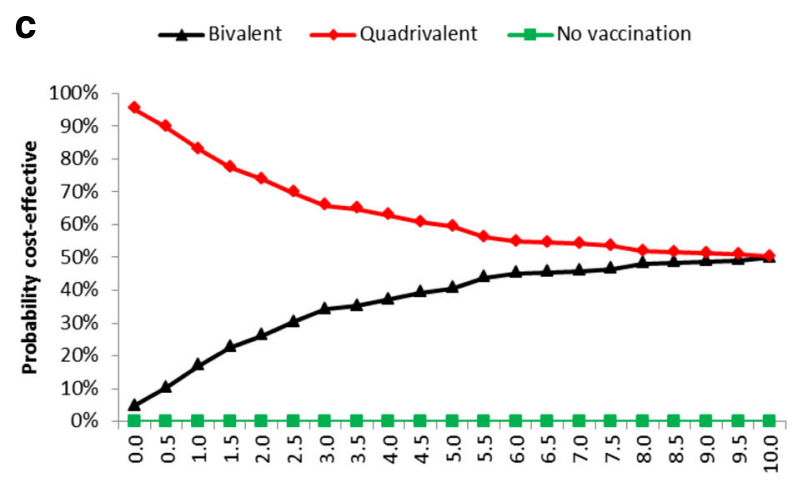

GDP per capita

Scenario 4

a

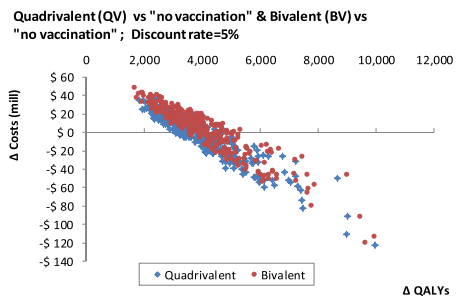

b

Bivalent vs Quadrivalent (BV-QV) Discount rate $=5 \%$

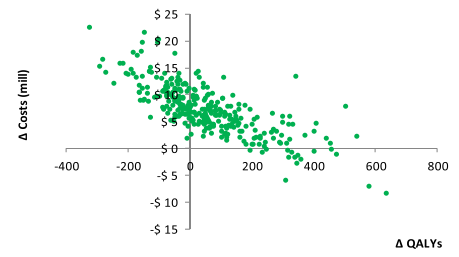

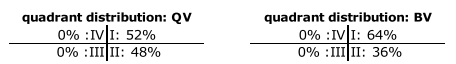

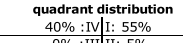

$0 \%:$ :IIIII: $5 \%$

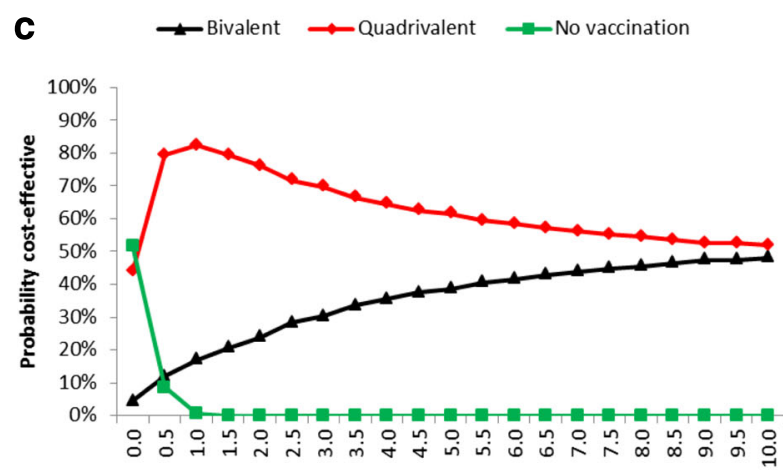

GDP per capita

Fig. 5 (See legend on next page.) 
(See figure on previous page.)

Fig. 5 Probabilistic sensitivity analysis - Scatter plots for a) costs and b) QALYs differences, c) Cost-effectiveness acceptability curves (probability of being the most cost-effective intervention) for scenario 2 (same vaccine price per dose of 8.5 US\$, exchange rate of $6.3 \mathrm{VEF}$, scheme of 2 doses) and scenario 4 (same vaccine price per dose of 8.5 US\$, exchange rate of $170 \mathrm{VEF}$, scheme of 2 doses). Discount rate $=5 \%$. Abbreviations: VEF: Venezuelan bolívar fuerte; US\$: United States dollar; GDP: Gross Domestic Product

studies. Our main findings were that HPV vaccination in 11-year-old girls in Venezuela would significantly reduce HPV-related diseases, and that they would be either cost-saving or cost-effective in all scenarios. Both the bivalent and quadrivalent vaccines showed similar results against no vaccination.

On six scenarios assessed, avoided costs were greater than costs of vaccination, resulting in cost-saving strategies. In two scenarios only - those using higher exchange rates and differential vaccines costs-vaccination was more costly than current screening. Nevertheless, in both cases, both vaccines were cost-effective, with costs per QALYs of less than 1 GDP per capita.

While the bivalent vaccine reduced a larger number of $\mathrm{CC}$ cases and deaths as compared with the quadrivalent vaccine, the quadrivalent reduced also the number of GWs. The net effect was a slight difference in LYs and QALYs in favor of the bivalent vaccine, though these results were highly dependent on the assumptions of the study, especially in cross-protection and incidence of GW.

It was clear and consistent that any vaccination strategy for HPV prevention would not only be beneficial for the health of women in Venezuela, but it would also be cost-saving or cost-effective, and thus a good intervention from the public health point of view. There was uncertainty regarding the relative cost-effectiveness of both vaccines. Accordingly, it is difficult to draw conclusions on the comparative performance of the different vaccines since the results are less clear and had significant heterogeneity in the tested scenarios: in some scenarios the bivalent vaccine was cost-saving or cost-effective compared to the quadrivalent, while in others it was clearly not.

\section{Conclusions}

Despite uncertainty in Venezuela concerning costs data, exchange rates and epidemiological parameters, the main conclusion of the present study is that HPV vaccination provides significant health benefits, being either a cost-saving or a cost-effective strategy against the current practice of screening and no vaccination.

Given the uncertainties identified and because of the relatively similar overall benefit of both vaccines measured in LYS or QALYs, the decision of choosing one vaccine over another should take into consideration not only the cost-effectiveness, but also other aspects that differentiate both vaccines that can be valued in the local context.

\section{Additional file}

Additional file 1: Presents the tornado graphs for deterministic sensitivity analyses and scatter plots for costs and QALYs/cost-effectiveness acceptability curves for probabilistic sensitivity analyses for scenarios 1, 3, 5 and 7 (3-dose schemes), and scenarios 2 and 4 (2-dose schemes). Also presents micro-costing details. (DOCX $698 \mathrm{~kb}$ )

\section{Abbreviations}

CC: Cervical cancer; CEAC: Cost-effectiveness acceptability curves; CIN: Cervical intraepithelial neoplasia; DSA: Deterministic sensitivity analysis; GDP: Gross domestic product; GW: Genital warts; HPV: Human Papillomavirus; ICER: Incremental cost-effectiveness ratio; LAC: Latin America and the Caribbean region; LYs: Life-years; PAHO: Pan American Health Organization; Pap: Papanicolaou smear test; PSA: Probabilistic sensitivity analysis; QALYs: Quality-adjusted life years; VEF: Venezuelan bolívar fuerte

\section{Acknowledgements}

We thank Dr. Luis G Capote-Negrín (Regional coordinator of the Cancer Registry, Ministry of Health, Venezuela) and Dr. Jorge Sánchez-Lander (Gynecology Department, Oncology Institute "Dr. Luis Razetti", Caracas, Venezuela) for providing data for the elaboration of this report and librarian Daniel Comandé at IECS for his help with the electronic searches. We also thank Marcela Perez (Random Foundation on behalf of GSK) and Maria A. Clavijo Salomón (Random Foundation on behalf of GSK at the time of writing and currently University of Sao Paulo, Institute of Biomedical Sciences) for medical writing assistance, Ingrid Leal and Sylvia Amador (GSK) for publication development support. Editorial support was provided by Gregory Collet (Business \& Decision Life Sciences on behalf of GSK).

\section{Funding}

GlaxoSmithKline Biologicals SA was the funding source and was involved in all study activities (GSK study identifier: HO-14-14442) and overall data management (collection, analysis and interpretation). GlaxoSmithKline Biologicals SA also funded all costs associated with the development and the publishing of the present manuscript. All authors had full access to the data and the corresponding author was responsible for submission of the publication.

\section{Availability of data and materials}

GSK discloses, upon authorization or termination of development of a medicine, anonymized patient-level data from that interventional study will be made available to independent researchers, subject to review by an independent panel, at www.clinicalstudydatarequest.com. To further protect the privacy of patients and individuals involved in our studies, GSK does not publicly disclose subject level data. Please get back to corresponding author regarding further questions on raw data or model sharing.

\section{Authors' contributions}

AB, OUG, MC, APR, FA, SGM, LN, JAG and JC participated to the conception/ design of the review; $A B, O U G, M C, A P R, P C, M G, J A G$ and JC participated to the collection/assembling of the data; AB, OUG, MC, APR, FA, SGM, PC, LN, $J A G$ and JC performed/supervised the analysis; AB, OUG, MC, APR, FA, SGM, $P C, M G, L N, J A G$ and JC participated to the interpretation of the data; MG participated to the application of the methodology in the specific case of Venezuela. All authors read and approved the final manuscript.

\section{Competing interests}

The authors have sole responsibility for the writing and content of the paper. APR, SGM, AF, AB, MC, JC, OUG have nothing to disclose; JAG is an employee of the GSK group of companies and holds shares from the GSK group of companies; IECS has received grants from the GSK group of companies 
during the conduct of the study and grants from MSD outside the submitted work; LN is an employee of the GSK group of companies; MG reports personal fees from the GSK group of companies during the conduct of the study and personal fees from the GSK group of companies outside the submitted work (participation to the HPV Payers Advisory Board, Panama City, June 15th, 2012); PC reports personal fees from the GSK group of companies during the conduct of the study and personal fees from Roche, Bayer and MSD outside the submitted work.

\section{Consent for publication}

Not applicable.

\section{Ethics approval and consent to participate}

Not applicable.

\section{Trademark section}

Cervarix is a trademark of the GSK group of companies.

Gardasil is a trademark of Merck

\section{Author details}

'IECS Instituto de Efectividad Clínica y Sanitaria, Dr. Emilio Ravignani 2024 (C1014CPV), 1014 Buenos Aires, Argentina. ${ }^{2}$ Salud Chacao, Final Av. Ávila, Edif. Salud Chacao. Urb. Bello Campo. Chacao, 1060 Caracas, D.C, Venezuela. ${ }^{3}$ Unit of Public Policy, Simon Bolivar University, Edificio Física y Electrónica I, Planta Baja. Valle de Sartenejas, Estado Miranda Caracas, Venezuela.

${ }^{4}$ GlaxoSmithKline Biologicals, Clayton, Ciudad del Saber Edificio 230, Panama City, Panama. ${ }^{5}$ GSK Vaccines Latin America, Carlos Casares 3690, B1644 BCD Victoria, Buenos Aires, Argentina.

Received: 2 April 2016 Accepted: 24 January 2017 Published online: 02 February 2017

\section{References}

1. Demarteau N, Van Kriekinge G, Simon P. Incremental cost-effectiveness evaluation of vaccinating girls against cervical cancer pre- and post-sexual debut in Belgium. Vaccine. 2013;31(37):3962-71.

2. Pierce Campbell CM, Curado MP, Harlow SD, Soliman AS. Variation of cervical cancer incidence in Latin America and the Caribbean. Rev Panam Salud Publica. 2012;31(6):492-8

3. Arrossi S, Sankaranarayanan R, Parkin DM. Incidence and mortality of cervical cancer in Latin America. Salud Publica Mex. 2003;45 Suppl 3:S306-14.

4. XIV National Census of Population and Housing. In. Bolivarian Republic of Venezuela: National Institute of Statistics 2011.

5. Human Papillomavirus and Related Disease Report. Venezuela. In.: WHO/ICO Information Centre on Human Papilloma Virus (HPV) and Cervical Cancer; 2013.

6. National Mortality Yearbook 2011. In. Bolivarian Republic of Venezuela: Ministry of Health.; 2014: 389.

7. Wierzbicka M, Jozefiak A, Jackowska J, Szydlowski J, Gozdzicka-Jozefiak A HPV vaccination in head and neck HPV-related pathologies. Otolaryngol Pol. 2014;68(4):157-73.

8. Wakeham K, Kavanagh K. The burden of HPV-associated anogenital cancers. Curr Oncol Rep. 2014;16(9):402

9. Jacobs MV, de Roda Husman AM, van den Brule AJ, Snijders PJ, Meijer CJ, Walboomers JM. Group-specific differentiation between high- and low-risk human papillomavirus genotypes by general primer-mediated PCR and two cocktails of oligonucleotide probes. J Clin Microbiol. 1995;33(4):901-5.

10. Munoz N. Human papillomavirus and cancer: the epidemiological evidence. J Clin Virol. 2000;19(1-2):1-5.

11. Bosch FX, Lorincz A, Munoz N, Meijer CJ, Shah KV. The causal relation between human papillomavirus and cervical cancer. J Clin Pathol. 2002;55(4):244-65.

12. Munoz N. From causality to prevention - the example of cervical cancer: my personal contribution to this fascinating history. Public Health Genomics. 2009;12(5-6):368-71

13. Walboomers JM, Jacobs MV, Manos MM, Bosch FX, Kummer JA, Shah KV, Snijders PJ, Peto J, Meijer CJ, Munoz N. Human papillomavirus is a necessary cause of invasive cervical cancer worldwide. J Pathol. 1999;189(1):12-9.

14. Correnti M, Medina F, Cavazza ME, Rennola A, Avila M, Fernandes A. Human papillomavirus (HPV) type distribution in cervical carcinoma, low-grade, and high-grade squamous intraepithelial lesions in Venezuelan women. Gynecol Oncol. 2011;121(3):527-31.
15. Sanchez-Lander J, Cortinas P, Loureiro CL, Pujol FH, Medina F, CapoteNegrin L, Bianchi G, Garcia-Barriola V, Ruiz-Benni A, Avilan-Rovira J, et al. Human papillomavirus in invasive cervical cancer and cervical intraepithelial neoplasia 2 and 3 in Venezuela: a cross-sectional study. Cancer Epidemiol. 2012;36(5):e284-7

16. Giorgi Rossi P, Baldacchini F, Ronco G. The Possible Effects on SocioEconomic Inequalities of Introducing HPV Testing as Primary Test in Cervical Cancer Screening Programs. Frontiers Oncol. 2014;4:20.

17. Basu P, Banerjee D, Singh P, Bhattacharya C, Biswas J. Efficacy and safety of human papillomavirus vaccine for primary prevention of cervical cancer: A review of evidence from phase III trials and national programs. South Asian J Cancer. 2013;2(4):187-92.

18. Demarteau N, Tang CH, Chen HC, Chen CJ, Van Kriekinge G. Costeffectiveness analysis of the bivalent compared with the quadrivalent human papillomavirus vaccines in Taiwan. Value Health. 2012;15(5):622-31.

19. Van de Velde N, Boily MC, Drolet M, Franco EL, Mayrand MH, Kliewer EV, Coutlee F, Laprise JF, Malagon T, Brisson M. Population-level impact of the bivalent, quadrivalent, and nonavalent human papillomavirus vaccines: a model-based analysis. J Natl Cancer Inst. 2012;104(22):1712-23.

20. De Vincenzo R, Conte C, Ricci C, Scambia G, Capelli G. Long-term efficacy and safety of human papillomavirus vaccination. Int J Women's Health. 2014;6:999-1010.

21. Murillo R, Almonte M, Pereira A, Ferrer E, Gamboa OA, Jeronimo J, LazcanoPonce E. Cervical cancer screening programs in Latin America and the Caribbean. Vaccine. 2008;26 Suppl 11:L37-48.

22. Colantonio L, Gomez JA, Demarteau N, Standaert B, Pichon-Riviere A, Augustovski F. Cost-effectiveness analysis of a cervical cancer vaccine in five Latin American countries. Vaccine. 2009;27(40):5519-29.

23. Goldie SJ, Kohli M, Grima D, Weinstein MC, Wright TC, Bosch FX, Franco E. Projected clinical benefits and cost-effectiveness of a human papillomavirus 16/18 vaccine. J Natl Cancer Inst. 2004;96(8):604-15.

24. Suarez E, Smith JS, Bosch FX, Nieminen P, Chen CJ, Torvinen S, Demarteau $N$, Standaert B. Cost-effectiveness of vaccination against cervical cancer: a multi-regional analysis assessing the impact of vaccine characteristics and alternative vaccination scenarios. Vaccine. 2008;26 Suppl 5:F29-45.

25. Anonychuk AM, Bauch CT, Merid MF, Van Kriekinge G, Demarteau N. A cost-utility analysis of cervical cancer vaccination in preadolescent Canadian females. BMC Public Health. 2009:9:401.

26. Debicki D, Ferko N, Demarteau N, Gallivan S, Bauch C, Anonychuk A, Mantovani L, Capri S, Chou CY, Standaert B, et al. Comparison of detailed and succinct cohort modelling approaches in a multi-regional evaluation of cervical cancer vaccination. Vaccine. 2008;26 Suppl 5:F16-28.

27. Demarteau N, Standaert B. Modelling the economic value of cross- and sustained-protection in vaccines against cervical cancer. J Med Econ. 2010;13(2):324-38.

28. Gomez JA, Lepetic A, Demarteau N. Health economic analysis of human papillomavirus vaccines in women of Chile: perspective of the health care payer using a Markov model. BMC Public Health. 2014;14:1222.

29. Núñez-Troconis J, Delgado M, González J, Mindiola R, Velásquez J, Conde B, Whitby D, Munroe DJ. Prevalence and risk factors of human papillomavirus infection in asymptomatic women in a Venezuelan urban area. Invest clín. 2009;50(2):203-12

30. Ferreccio C, Prado RB, Luzoro AV, Ampuero SL, Snijders PJ, Meijer CJ, Vaccarella SV, Jara AT, Puschel Kl, Robles SC, et al. Population-based prevalence and age distribution of human papillomavirus among women in Santiago, Chile. Cancer Epidemiol Biomarkers Prev. 2004;13(12):2271-6.

31. Kraut AA, Schink T, Schulze-Rath R, Mikolajczyk RT, Garbe E. Incidence of anogenital warts in Germany: a population-based cohort study. BMC Infect Dis. 2010;10:360.

32. Scarbrough Lefebvre CD, Van Kriekinge G, Goncalves MA, de Sanjose S. Appraisal of the burden of genital warts from a healthcare and individual patient perspective. Public Health. 2011;125(7):464-75.

33. Avila M, Cavazza M, Vasquez W, Ortega J, Lopez Y, Correnti M. Genotipificación del virus de papiloma humano en pacientes con condilomas acuminados. Rev Soc Venez Microbiol. 2008;28:127-33.

34. Petry KU. Management options for cervical intraepithelial neoplasia. Best Pract Res Clin Obstet Gynaecol. 2011;25(5):641-51.

35. Melnikow J, McGahan C, Sawaya GF, Ehlen T, Coldman A. Cervical intraepithelial neoplasia outcomes after treatment: long-term followup from the British Columbia Cohort Study. J Natl Cancer Inst. 2009; 101(10):721-8. 
36. Rodríguez A, Santos M, Noguera M, Romero L. Seguimiento y sobrevida de pacientes con carcinoma invasor del cuello uterino. Rev Obstet Ginecol Venez. 2008;68(2):81-6.

37. Official Standard for Comprehensive Sexual and Reproductive Health..In. Bolivarian Republic of Venezuela: Ministry of Health; 2013.

38. Medina F, Sanchez-Lander J, Calderaro F, Borges A. Cancer de Cuello Uterino. Consenso Nacional para el Diagnostico y Tratamiento. Rev Venez Oncol 2011. 2010;23(2):102-29.

39. Public Tariff of services. In. Caracas, Venezuela: Official Journal of Bolivarian Republic of Venezuela; 2013

40. Gonzalez MRE, Mijares R. I Encuesta Nacional de Salud. Venezuela 2011. Resultados: preguntas de cobertura de seguros. Caracas: FUNINDES-USB, Unidad de Políticas Públicas; 2013.

41. Insituto Nacional de Estadística, República Bolivariana de Venezuela. Indice Nacional de Precios al Consumidor [http://www.ine.gov.ve/index.php?option= com_content\&view=category\&id=108\&ltemid=62 Accessed Dec 2015]

42. Pan American Health Organization: PAHO Revolving Fund. Vaccine prices. 2013. http://www.paho.org/hq/index.php?option=com_content\&view= article\&id=1864\%3A2014-paho-revolving-fund\&catid=839\%3Arevolvingfund\&ltemid=4135\&lang=en Accessed 24 July 2015.

43. Paavonen J, Naud P, Salmeron J, Wheeler CM, Chow SN, Apter D, Kitchener H, Castellsague X, Teixeira JC, Skinner SR, et al. Efficacy of human papillomavirus (HPV)-16/18 AS04-adjuvanted vaccine against cervical infection and precancer caused by oncogenic HPV types (PATRICIA): final analysis of a double-blind, randomised study in young women. Lancet. 2009;374(9686):301-14.

44. Romanowski B, de Borba PC, Naud PS, Roteli-Martins CM, De Carvalho NS, Teixeira JC, Aoki F, Ramjattan B, Shier RM, Somani R, et al. Sustained efficacy and immunogenicity of the human papillomavirus (HPV)-16/18 AS04adjuvanted vaccine: analysis of a randomised placebo-controlled trial up to 6.4 years. Lancet. 2009;374(9706):1975-85.

45. Future II Study Group. Quadrivalent vaccine against human papillomavirus to prevent high-grade cervical lesions. N Engl J Med. 2007;356(19):1915-27.

46. Brown DR, Kjaer SK, Sigurdsson K, Iversen OE, Hernandez-Avila M, Wheeler CM, Perez G, Koutsky LA, Tay EH, Garcia P, et al. The impact of quadrivalent human papillomavirus (HPV; types $6,11,16$, and 18) L1 virus-like particle vaccine on infection and disease due to oncogenic nonvaccine HPV types in generally HPV-naive women aged 16-26 years. J Infect Dis. 2009;199(7):926-35.

47. Skinner SR AD, Chow SN, Wheeler C, Dubin G; for the HPV PATRICIA Study Group,: International Papillomavirus Conference and Clinical Workshop, Malmö, 2009. Cross-protective efficacy of Cervarix ${ }^{\mathrm{TM}}$ against oncogenic hpv types beyond hpv-16/18: final analysis of cross-protection - PATRICIA study. Page 67/69. 2009.

48. Szarewski A. HPV vaccine: Cervarix. Expert Opin Biol Ther. 2010;10(3):477-87.

49. Tjalma W. 16th International meeting of the European Society of Gynaecological Oncology (ESGO). Serbia: Belgrade; 2009. Efficacy of the HPV-16/18 AS04-adjuvanted vaccine against abnormal cytology and lowgrade histopathological lesions in an oncogenic HPV-naïve population.

50. Wheeler CM, Castellsague X, Garland SM, Szarewski A, Paavonen J, Naud P, Salmeron J, Chow SN, Apter D, Kitchener H, et al. Cross-protective efficacy of HPV-16/18 AS04-adjuvanted vaccine against cervical infection and precancer caused by non-vaccine oncogenic HPV types: 4-year end-of-study analysis of the randomised, double-blind PATRICIA trial. Lancet Oncol. 2012;13(1):100-10.

51. Goldie SJ, O'Shea M, Diaz M, Kim SY. Benefits, cost requirements and cost-effectiveness of the HPV16,18 vaccine for cervical cancer prevention in developing countries: policy implications. Reprod Health Matters. 2008;16(32):86-96.

52. Romanowski B, Schwarz TF, Ferguson L, Peters K, Dionne M, Behre U, Schulze K, Hillemanns P, Suryakiran P, Thomas F, et al. Sustained immunogenicity of the HPV-16/18 AS04-adjuvanted vaccine administered as a two-dose schedule in adolescent girls: Five-year clinical data and modeling predictions from a randomized study. Hum Vaccines Immunotherapeut. 2015;1-10.

53. Moscicki AB, Wheeler CM, Romanowski B, Hedrick J, Gall S, Ferris D, Poncelet S, Zahaf T, Moris P, Geeraerts B, et al. Immune responses elicited by a fourth dose of the HPV-16/18 AS04-adjuvanted vaccine in previously vaccinated adult women. Vaccine. 2012;31(1):234-41.

54. Kreimer AR, Rodriguez AC, Hildesheim A, Herrero R, Porras C, Schiffman M, Gonzalez P, Solomon D, Jimenez S, Schiller JT, et al. Proof-of-principle evaluation of the efficacy of fewer than three doses of a bivalent HPV16/18 vaccine. J Natl Cancer Inst. 2011;103(19):1444-51.

55. Puthanakit T, Huang L, Tang R, Schwarz T, Esposito S, Frenette L, McNeil S, Rheault P, Horn M, Klar M. Paediatric Infectious Diseases Meeting. Dublin,
Ireland. Non-Inferiority of HPV -16/18 AS04-adjuvanted vaccine administered as 2-dose chedules in girls (9-14 years) versus 3 doses in women (15-25 years): A randomised controlled trial..In.; 2014.

56. Romanowski $B$, Schwarz TF, Ferguson LM, Ferguson M, Peters $K$, Dionne $M$, Schulze K, Ramjattan B, Hillemanns P, Behre U, et al. Immune response to the HPV-16/18 AS04-adjuvanted vaccine administered as a 2-dose or 3-dose schedule up to 4 years after vaccination: results from a randomized study. Human Vaccines Immunotherapeutics. 2014;10(5):1155-65.

57. Romanowski B, Schwarz TF, Ferguson LM, Peters K, Dionne M, Schulze K, Ramjattan B, Hillemanns P, Catteau G, Dobbelaere K, et al. Immunogenicity and safety of the HPV-16/18 AS04-adjuvanted vaccine administered as a 2dose schedule compared with the licensed 3-dose schedule: results from a randomized study. Human vaccines. 2011;7(12):1374-86.

58. Hernandez-Avila M, Torres-Ibarra L, Stanley M, Salmeron J, Cruz-Valdez A, Munoz N, Herrero R, Villasenor-Ruiz IF, Lazcano-Ponce E. Evaluation of the immunogenicity of the quadrivalent HPV vaccine using 2 versus 3 doses at month 21: An epidemiological surveillance mechanism for alternate vaccination schemes. Human Vaccines Immunotherapeutics. 2015;1-9.

59. Augustovski F, Garay OU, Pichon-Riviere A, Rubinstein A, Caporale JE. Economic evaluation guidelines in Latin America: a current snapshot. Expert Rev Pharmacoecon Outcomes Res. 2010;10(5):525-37.

60. Insinga RP, Dasbach EJ, Elbasha EH. Epidemiologic natural history and clinical management of Human Papillomavirus (HPV) Disease: a critical and systematic review of the literature in the development of an HPV dynamic transmission model. BMC Infect Dis. 2009;9:119.

61. Briggs A SM, Claxton K. Decision Modelling for Health Economic Evaluation. Handbooks in Health Economic Evaluation. Oxford University Press 2006.

62. Fenwick E, Claxton K, Sculpher M. Representing uncertainty: the role of cost-effectiveness acceptability curves. Health Econ. 2001;10(8):779-87.

63. Ferlay J, Soerjomataram I, Ervik M, Dikshit R, Eser S, Mathers C, Rebelo M, Parkin D, Forman D, Bray F. GLOBOCAN 2012 v1.0, Cancer Incidence and Mortality Worldwide: IARC CancerBase No. 11 [Internet]. Lyon: International Agency for Research on Cancer; 2013.

64. Demarteau N, Detournay B, Tehard B, El Hasnaoui A, Standaert B. A generally applicable cost-effectiveness model for the evaluation of vaccines against cervical cancer. Int J Public Health. 2011;56(2):153-62.

65. Woodhall SC, Jit M, Soldan K, Kinghorn G, Gilson R, Nathan M, Ross JD, Lacey CJ. The impact of genital warts: loss of quality of life and cost of treatment in eight sexual health clinics in the UK. Sex Transm Infect. 2011;87(6):458-63.

66. Garland SM, Hernandez-Avila M, Wheeler CM, Perez G, Harper DM, Leodolter S, Tang GW, Ferris DG, Steben M, Bryan J, et al. Quadrivalent vaccine against human papillomavirus to prevent anogenital diseases. N Engl J Med. 2007;356(19):1928-43.

67. Munoz N, Kjaer SK, Sigurdsson K, Iversen OE, Hernandez-Avila M, Wheeler CM, Perez G, Brown DR, Koutsky LA, Tay EH, et al. Impact of human papillomavirus (HPV)-6/11/16/18 vaccine on all HPV-associated genital diseases in young women. J Natl Cancer Inst. 2010;102(5):325-39.

68. The World Bank. World Development Indicator Database [Available at: http://data.worldbank.org/indicator/NY.GDP.PCAP.CN.]

\section{Submit your next manuscript to BioMed Central and we will help you at every step:}

- We accept pre-submission inquiries

- Our selector tool helps you to find the most relevant journal

- We provide round the clock customer support

- Convenient online submission

- Thorough peer review

- Inclusion in PubMed and all major indexing services

- Maximum visibility for your research

Submit your manuscript at www.biomedcentral.com/submit 